\title{
perifèria
}

Número 20 (2), diciembre2015

revistes.uab.cat/periferia

\section{Bailando la diferencia: identidades culturales y música salsa en Barcelona}

\author{
Isabel Llano - Universitat Autònoma de Barcelona
}

DOI: http://dx.doi.org/10.5565/rev/periferia.487

\begin{abstract}
Resumen
En el baile de la salsa hay muchos estilos. En Barcelona, el estilo cubano fue el primero en difundirse a inicios de 1990. Sin embargo, el estilo Los Ángeles comenzó a proliferar desde comienzos de 2000, a la vez que empezó a replicarse el modelo de los congresos de salsa a nivel mundial. La internacionalización del baile de la salsa coincidió con el boom de la inmigración latinoamericana en España, por lo que la emergencia de las primeras escuelas y compañías de baile de salsa dirigidas al público local, a principios del nuevo siglo, ocurrió paralelamente a la apertura de nuevas discotecas de salsa, merengue y bachata dirigidas a los residentes latinoamericanos. Dada la programación de salsa, realizada por las discotecas y salas de baile, sería posible dar por hecho que los latinoamericanos residentes en Barcelona y los autóctonos convergen en estos espacios, sin embargo, la realidad es otra. Considerando el concepto kinetopia, en este artículo aportamos un análisis sobre la oposición de "baile de escuela" y "baile callejero", que explicaría la segmentación de los espacios de baile de la salsa en Barcelona, más allá de las diferencias culturales.
\end{abstract}

Palabras clave: Salsa, Barcelona, inmigración, kinetopia

\begin{abstract}
There are many styles of salsa dancing. In Barcelona, the Cuban style was the first one disseminated in the early nineties. However, Los Angeles style began to proliferate from the first years of the new century, while the model of salsa congresses began to be replicated worldwide. The internationalization of salsa dancing coincided with the boom of Latin American immigration in Spain, so the emergence of the first schools and salsa dance companies aimed to the local audiences in the early new century, occurred in parallel with the emergence of the new discotheques of salsa, merengue and bachata directed to Latin American residents. Given the salsa offer, made by the discotheques and dance halls, it would be possible to assume that Latin Americans living in Barcelona and the Spaniards converge in these spaces; however, the reality is different. Bearing in mind the concept kinetopia, in this article we provide an analysis of the opposition of "studio dance" and "street dance", which would explain the segmentation of places of salsa dancing in Barcelona, beyond cultural differences.
\end{abstract}

Key words: Salsa dancing, Barcelona, immigration, kinetopia

\footnotetext{
${ }^{1}$ Enviar correspondencia a: Isabel Llano- isa_Ilano@hotmail.com
} 


\section{perifèria}

Número 20 (2), diciembre2015

revistes.uab.cat/periferia

\section{Música, baile e identidad ${ }^{2}$}

La música es un importante articulador de identidades colectivas. Diversas investigaciones han abordado el tema de la música y el baile como mediadores de las relaciones interculturales de grupos diferenciados en contextos urbanos (Wade 2000, Patria Román-Velásquez 1999, Sánchez 2008, entre muchas otras). En Barcelona, la inmigración latinoamericana es un hecho, y su presencia no solo en esta ciudad sino en el país tiene un carácter irreversible. El asentamiento de extranjeros planteamuchos desafíos a nivel político y cultural, pero, teniendo en cuenta los nexos culturales entre españoles y latinos, y considerando que para los latinos sus expresiones culturales más importantes son la música y el baile, es posible que estas manifestaciones identitarias, ligadas a la fiesta, permitan un acercamiento mayor entre ambos grupos, aunque ese intercambio seguramente propicie ciertas transformaciones identitarias, pues como señala Wade (2000: 210), la música - y en particular el baile- se presta a procesos de incorporación y transformación de la identidad, o como explica Escalona (2010: 37), la fiesta y el baile hacen posible encontrarse con la alteridad, no solo con la externa sino la que nos habita.

También hemos de tener en cuenta, como anota Josep Martí, que:

"Las fiestas que se celebran en la inmigración experimentan procesos de resemantización perfectamente lógicos. Resulta fácil entender que estas fiestas adquieran ciertos rasgos etnicitarios que no forzosamente han de tener en sus lugares de origen" (Martí 2008: 35).

\footnotetext{
${ }^{2}$ Este articulo retoma resultados de la tesis doctoral realizada dentro del programa de Periodismo en la Facultad de Ciencias de la Comunicación de la UAB, titulada La salsa en Barcelona: inmigración, identidad, músicas latinas y baile, dirigida por Josep Martí i Pérez (CSIC). El análisis respecto a lo que aquí se presenta está basado en datos empíricos recabados en Barcelona. A la observación participante realizada desde comienzos de 2000 en discotecas, salas y eventos de baile, se suman 32 entrevistas en profundidad llevadas a cabo entre 2006 y 2015, con bailarines, bailadores,profesores de baile, DJs, músicos y aficionados a la salsa.
} 


\section{perifèria}

Número 20 (2), diciembre2015

revistes.uab.cat/periferia

Por tanto, estudiar las relaciones de latinos y españoles mediadas por la salsa y su baile en Barcelona nos ayudaa saber qué alianzas o separaciones sociales se construyen a través de las diferencias étnicas de los participantes del baile, cómo se reconstruyen las identidades de latinos en un contexto nuevo, y cómo se negocian las identidades de los españoles por la aproximación a esta música y su baile.

\section{El baile de la Salsa: localización de una práctica global}

El baile de la salsa no es uno solo, hay muchos estilos, entre los más conocidos internacionalmente están el cubano, el puertorriqueño, la salsa en línea (que incluye los estilos de Nueva York y Los Ángeles) y la salsa colombiana. En Barcelona, el estilo cubano o rueda de casino fue el primero en difundirse, especialmente a comienzos de los años noventa. Sin embargo, la salsa en línea, -en particular el estilo Los Ángeles- comenzó a proliferar desde los primeros años del nuevo siglo, a la vez que empezó a replicarse el modelo de los congresos de salsa a nivel mundial ${ }^{3}$.

La internacionalización del baile de la salsa coincidió con el boom de la inmigración latinoamericana en España ${ }^{4}$, por lo que la emergencia de las primeras escuelas y compañías de baile de salsa dirigidas al público local, a principios del nuevo siglo, ocurrió paralelamente a la aparición de emisoras de radio latinas y la apertura de nuevas discotecas de salsa, merengue y bachata dirigidas a los nuevos residentes latinoamericanos.

Dada la programación de salsa y otras músicas asociadas con el Caribe, realizada por las discotecas y salas de baile, sería posible dar por hecho que los latinoamericanos residentes en Barcelona y los autóctonos convergen sin

\footnotetext{
${ }^{3}$ Denominamos congresos de salsa en general a los eventos de carácter nacional o internacional en torno a los bailes latinos. En estos el público puede oscilar entre 400 y 1500 personas según el caso. Dependiendo de los objetivos y características de cada evento, el nombre puede variar entre congreso, campeonato, festival, simposio, weekend o encuentro y pueden tener un carácter competitivo.

${ }^{4}$ Entendemos por boom de la inmigración latinoamericana a la rápida elevación del número de personas de nacionalidad latinoamericana que constaban empadronadas en España, y particularmente en Barcelona entre los años 2000 y2010.
} 


\section{perifèria}

Número 20 (2), diciembre2015

\section{revistes.uab.cat/periferia}

inconveniente en estos espacios, pues los latinos se identifican culturalmente y bailan estas músicas, y los españoles han aprendido a bailar estos ritmos y han desarrollado gran afición a la práctica de esos bailes. Sin embargo, la realidad es otra. Si bien hasta finales de los años noventas los pocos latinoamericanos que residían en Barcelona coincidían en las primeras discotecas de salsa con la gente nacida aquí y daban un sello de autenticidad, desde mediados de la primera década de 2000, salvo contadas excepciones, la población de origen latinoamericano suele ir a bailar a unas determinadas discotecas, mientras que la población autóctona acostumbra a ir a otras ${ }^{5}$.

La separación de los espacios de baile y, por consiguiente, de latinos y no latinos ${ }^{6}$, e incluso entre los diferentes grupos de latinos, se fue haciendo mayor desde comienzos del año 2000, el año en que empieza el auge de la inmigración latinoamericana. Esta separación ha obedecido a cierto tipo de exclusiones /inclusiones sociales entre ambos colectivos y entre los diferentes grupos de latinos. Los prejuicios respecto a rasgos físicos, la atribución de comportamientos legitimados/deslegitimados y la diferencia entre la fiesta "latina" y "española" (por ejemplo, respecto a las formas de consumo de licor) son algunos de los factores que están detrás de las inclusiones y exclusiones sociales. La segmentación de los espacios de baile de los latinos y de los no latinos también está asociada a la práctica de los diferentes estilos de baile que caracteriza a cada colectivo. En la base de esta división está la oposición entre "baile de escuela" y "baile callejero", es decir entre bailarines y bailadores ${ }^{7}$.

\footnotetext{
${ }^{5}$ Para mayores detalles sobre la emergencia de discotecas, escuelas y congresos de salsa en Barcelona ver el capítulo "Salsa in Barcelona and Spain" (Llano 2014).

${ }^{6}$ Usamos la categoría latinos para facilitar nuestra aproximación y manera de nombrar los grupos interculturales que nos ocupan, esto es latinoamericanos y españoles. Al decir españoles o no latinos nos referimos a la población autóctona, que al igual que cuando decimos latinoamericanos, incluye personas diversas en características sociales, culturales y económicas, aunque se cuente entre ellas principalmente catalanes, además de otras personas de diferentes regiones del país, e incluso extranjeros no latinos residentes en Barcelona

${ }^{7}$ Resumiendo las definiciones aportadas por Alejandro Ulloa (2005:71) los bailarines asumen el baile como una práctica profesional o bien como una práctica para el espectáculo, por lo cual el baile está en relación con la enseñanza-aprendizaje de técnicas formales y ensayos. Los bailadores asumen el baile como una práctica lúdica ligada al placer, sin pretensiones de profesionalismo.
} 


\section{perifèria}

Número 20 (2), diciembre2015

revistes.uab.cat/periferia

Cuando hablamos del baile de escuela, nos referimos al baile aprendido en academias y tiene que ver, en general, con los no latinos. Corresponde a una forma estandarizada de baile según el estilo aprendido, que se puede apreciar incluso en lo que los bailarines Ilaman baile social, es decir cuando están de fiesta y no presentando en público una coreografía, pues es notable la homogenización de los movimientos de los cuerpos de los bailarines en la pista. El baile callejero, es el que se asocia por lo general a los latinos y al estilo de baile relacionado con un lugar geográfico concreto, que se ha aprendido por imitación y a menudo desde muy temprana edad en el hogar o en los bailes sociales. En consecuencia, aunque latinos y no latinos tienen en común el interés por bailar, la forma de vivir y considerar el baile por cada colectivo es diferente.

La oposición entre "baile de escuela" y "baile callejero" remite a diferencias entre los estilos de baile, pero también nos habla de diferencias culturales y separaciones sociales. Entre los estilos de baile transnacionales más relacionados con el baile callejero están el cubano o casino y el colombiano. No obstante, dentro de la categoría baile callejero están todas las maneras de bailar salsa que cada persona, sea de origen latinoamericano o no, ha aprendido sin mediación de una escuela. Entre los bailes de escuela se destaca la salsa en línea, especialmente el estilo Los Ángeles.

Nos interesa analizarla forma en que una práctica global como la salsa se vuelve local, en Barcelona. En este sentido retomamos el concepto kinetopia propuesto por Hutchinson para entender el fenómeno de la globalización de la salsa:

"Kinetopia" as a way of examining the interactions of dance with place. Its literal meaning is "place of movement", and the relationship functions in two ways: some dances are kinetopias, in that their relationship to place defines them, and some places are kinetopic, in that they are in part defined by their particular patterns of movement. [...] In other words, kinetopias are both places and dances: I am speaking of a dialectical relationship between localities and movement practices that is mediated through the body. The kinetopia concept can help us understand how people dance in place and why place-specific styles develop" (Hutchinson 2014: 15). 


\section{perifèria}

Número 20 (2), diciembre2015

revistes.uab.cat/periferia

En concreto analizamos el papel que juega la salsa y su baile en la construcción y negociación de identidades en el contexto de Barcelona. Es decir, abordamos la relación baile-identidad, y la circulación social del baile, considerando el baile, talcomo ha señalado Jane C. Desmond (1997: 49), un texto social principal (no secundario) de inmensa importancia, pues constituye un modo importante de distinción (Bourdieu 1998).

\section{Salsa de estudio}

En Barcelona, las clases que se ofrecen en las diversas escuelas o academias de baile se establecen por niveles, que van desde iniciación a avanzado y, a pesar de que en principio las clases son grupales, la mayoría de escuelas señala la posibilidad de tomar clases particulares así como de estilos femeninos o para chicas y de estilos para hombres. Muchas escuelas remarcan que no es necesario ir en pareja, aunque en la práctica es un inconveniente ir en solitario.

Los alumnos de las clases de baile saben que cuando van a inscribirse a un nivel diferente del inicial deben realizar una prueba de nivel, como ocurre por ejemplo cuando alguien se apuntaa un curso de idiomas.

Las escuelas, a pesar de enmarcar el baile como una práctica de enseñanzaaprendizaje de acuerdo con unas técnicas y estilos, señalan que se trata de "pasárselo bien" a la vez que se hace ejercicio, es decir, refieren al placer y los beneficios que proporciona el baile, como sucede en la práctica del baile por parte de los bailadores. Por consiguiente, aunque todas las escuelas son un negocio, algunas son más exigentes con los alumnos respecto a la técnica, mientras que otras priorizan que los alumnos se lo pasen bien. Los profesores son conscientes del alcance que tiene su escuela o el nivel máximo de la formación que pueden ofrecer. Asimismo, los alumnos que quieran continuar avanzando en su formación cambian de escuela a otra que les exija más, e incluso algunos empiezan a ejercer como profesores.

Los intereses de quienes toman clases van desde los que se las toman como ir al gimnasio, los que quieren hacer una actividad divertida o lograr un nivel avanzado 


\section{perifèria}

Número 20 (2), diciembre2015

revistes.uab.cat/periferia

en el baile, pasando por los que quieren competir en concursos y los que quieren formarse para vivir de la salsa (como profesores, haciendo shows, etc.). De acuerdo con las aspiraciones de cada quien se selecciona una u otra escuela según la reputación de la escuela, determinada por el prestigio de sus profesores. Entre los motivos por los que alguien, que no ha tenido relación desde la infancia con la salsa, se decide a iniciar clases están: el haber tenido una novia o pareja que ya practica el baile, provenir de los bailes de salón, considerar que la salsa es una práctica que facilita conocer personas y realizar actividades sociales.

Hay variedad de razones por las que los bailarines continuaron bailando salsa después de iniciar clases, y por las que continúan haciéndolo: desde poder coordinar pasos, pasando por desarrollar la actividad en sí y por las relaciones sociales que se realizan en torno a la salsa. Se observa que una vez se empieza a asistir a clases se entra en el circuito del baile de la salsa, aunque no necesariamente haya un interés por la música salsa; ya que para algunos la música tiene una función utilitaria, pues prácticamente no conocen nada sobre la historia del género ni sus orquestas ni cantantes más representativos.

\section{Salsa de calle}

La salsa de calle o el estilo de baile callejero suele asociarse por lo general a los latinos y a la manera de bailar característica en una ciudad o país en concreto, con la que se ha estado en relación desde muy temprana edad y que se ha aprendido en el hogar o en los bailes sociales. Sin embargo, en Barcelona, aparte de los latinos que tienen su propio estilo de baile según su lugar de procedencia (dominicanos, ecuatorianos, cubanos, colombianos...), encontramos a no latinos que, aunque hayan asistido a alguna clase de salsa, fundamentalmente han aprendido a bailar gracias a la interrelación con otros bailadores, a menudo latinos, 


\section{perifèria}

Número 20 (2), diciembre2015

revistes.uab.cat/periferia

aunque lo han hecho de adultos, no como los latinos que lo hacen desde niños y preadolescentes, sin pretensiones profesionales ${ }^{8}$.

El motivo por el cual los bailadores y bailadoras no latinas se engancharon a bailar salsa, tiene que ver con la alegría y la facilidad de relacionarse con los latinos que encontraron en torno al ambiente de la salsa, en comparación con otras discotecas no latinas, es decir el entorno que les era familiar. El interés por aproximarse a la cultura latinoamericana y por bailar, en cierta forma, y aunque no era el objetivo primordial, llevaba implícita la posibilidad de "ligar", la idea de seducción, por la cercanía que permite el baile en pareja. Hay que tener en cuenta que los comienzos de la relación de algunos bailadores y bailadores no latinos con la salsa remiten a los primeros años de los noventa, cuando había pocos latinoamericanos en Barcelona. Otros, estando de viaje, habían aprendido a bailar en un país latinoamericano. No obstante, en cuanto al interés por conocer la historia y los representantes de la música salsa hemos comprobado que no depende de que sea un bailarín o bailador, obedece a la curiosidad, al querer saber al respecto.

En los comentarios de bailadoras se mencionan implícita o explícitamente las diferencias que existen entre el baile de escuela y el baile callejero que ellas practican, es decir, las diferencias en la manera de bailar entre bailadores y bailarines, a las que nos referiremos a continuación.

\section{Bailarines frente bailadores: Memoria vs. Oído, sabor y sentimiento}

En el caso de los bailarines de origen latinoamericano se cumple que previamente a su aprendizaje formal del baile han sido bailadores. Sin embargo, hay casos de bailarines que aunque no asistieron a ninguna escuela han asumido el baile, además del placer que provoca, como una práctica profesional, para obtener una rentabilidad económica y simbólica. En estos casos, muchos de ellos cuentan en su trayectoria como bailarines bastantes años de formación y vemos que en cuanto ala

\footnotetext{
${ }^{8}$ Actualmente está habiendo un cambio, porque cada vez hay más niños que están empezando a tomar clases de salsa en Barcelona.
} 


\section{perifèria}

Número 20 (2), diciembre2015

revistes.uab.cat/periferia

relación con la música cubana y la salsa, los hay expertos, pero también los que en algunas ocasiones no tienen mayor conocimiento, a pesar de que su relación con la música se ha dado desde la niñez y en el ambiente familiar.

Así como los anteriores bailarines vienen de ser bailadores, tenemos casos de bailarines que cuando participan de la fiesta social (la rumba dirían los latinos bailadores) no se desligan de su función de bailarines, pues asumen el baile social recurriendo a lo que han aprendido en clase o en el montaje de coreografías. Los bailarines que fuera del escenario dependen de la memoria más que del oído, recuerdan secuencias, no improvisan movimientos según el ritmo la música y de la interrelación con la pareja de baile. Sobre la manera de enfrentarse al baile por parte de los bailarines en la fiesta social, tenemos que los bailarines aunque no estén en el escenario sino en la pista, están pensando en secuencias aprendidas y recurren a ellas, aunque puede que no encajen con la canción.

En algunos bailarines, además de observar las asociaciones que hacen con las técnicas de baile que conocen, podemos ver que establecen cierta jerarquía en el nivel de dificultad intrínseca a cada estilo de baile. El baile estilo cubano es más "sencillo" en comparación con el estilo de salsa en línea. Además, en la manera de asumir el baile por parte de algunos bailarines está la idea de que el baile son figuras que se memorizan y, entre ellos, hay casos de alumnos de baile que hacen figuras aprendidas de memoria, sin seguir el ritmo de la música.

El hecho de que para muchos bailarines el baile signifique hacer figuras y una repetición de secuencias aprendidas es uno de los aspectos más criticados por los bailadores latinos y no latinos. Este hecho está en la raíz de la preferencia de ciertos espacios de baile y por tanto de la separación de los diferentes colectivos.

Observamos que mientras en los testimonios de los bailarines prima la memoria en su experiencia del baile (qué secuencia hacer, si se está bailando bien según la técnica aprendida), los bailadores resaltan lo que sienten o les produce el baile como experiencia corporal. Los bailadores dicen dejarse llevar por el cuerpo en conexión con la música, y algunos establecen una relación del baile con lo sagrado, lo trascendente, lo mágico. Aunque esta experiencia trascendente es algo que no 


\section{perifèria}

Número 20 (2), diciembre2015

revistes.uab.cat/periferia

siempre se consigue con una pareja de baile, sino que ocurre de manera excepcional.

La experiencia de una epifanía entorno al baile de la salsa está en relación con lo que la investigadora Priscilla Renta, en su análisis sobre la salsa en Puerto Rico, ha llamado bailar salsa con sabor:

Sabor is the heart and soul of salsa dancing, an aesthetic tradition involving improvisation, creativity, and a corporeal response to the polyrhythmic quality of salsa music that stems from its African heritage (Renta 2014: 118).

Renta afirma que el sabor también envuelve aspectos espirituales y emocionales al tocar, escuchar y bailar música, que escapan a la verbalización, y nos recuerda que combinar lo sagrado y lo secular es común en la cultura latina. Bailar con sabor en este sentido es "to experience one's higher self, transcending material experience by surrendering to what the music enables dancers to feel in the present moment" (Renta 2014:122).

\section{Modificación de hábitos y transformaciones de la identidad a partir del baile}

En general los bailadores de calle critican a los bailarines de escuela por practicar un baile mecánico, acrobático, por bailar para lucirse sin escuchar y sentir la música, sin establecer una conexión con la pareja de baile, por la manera homogenizada en que bailan los bailarines. En suma, diríamos, por bailar sin sabor ni sentimiento. No obstante, algunos bailadores latinos de calle que han pasado a ser bailarines de escuela empiezan a dar un mayor estatus al baile de escuela. En su interés por cualificarse como bailarines, en aprender otros estilos y participar en compañías que realizan montajes coreográficos, es decir, en su proceso de profesionalización dentro del baile modifican sus hábitos respecto al baile, cambian los lugares elegidos para bailar y la valoración del baile callejero. Estos bailadores latinos de calle que se convierten en bailarines de escuela prefieren ir a las salas de 


\section{perifèria}

Número 20 (2), diciembre2015

revistes.uab.cat/periferia

baile de españoles en lugar de las discotecas de latinos y pasan a considerar negativamente el baile callejero que previamente practicaban.

Es interesante observar cómo el hecho de adquirir una formación técnica hace que los bailadores que vienen del baile callejero no solo otorgan un mayor estatus al baile de escuela, también hablan del baile en términos de limpieza o suciedad en relación al mayor o menor nivel técnico del baile, respectivamente.

También se asocia el haber empezado con el estilo propio, o baile callejero, como un lastre respecto al baile de escuela: el estilo callejero puede significar malas costumbres respecto a lo que se exige en el baile estilo línea, incluso, el hecho de ser latino, que suele relacionarse con la habilidad para el baile, puede sr puesto en cuestión cuando se trata de baile aprendido en escuela. Además, el baile callejero, según ciertos testimonios, puede considerarse antiguo, mientras que el baile de escuela es lo actual.

Si bien en los bailadores de calle se observa cómo la identidad se asocia a cierto tipo de baile y esta se pone en cuestión cuando se pasa del baile de calle al baile de escuela, en los bailarines de escuela se observa que, a partir de su experiencia en torno al baile, hay una transformación en la participación en ciertas comunidades, en la valoración del baile e incluso una modificación en la autovaloración. El bailar salsa se convierte en su actividad principal durante el tiempo libre y llegan a hablar de la salsa como "un virus", es decir, una vez te contagias ya tienes un virus incurable, otros hablan de la salsa como adicción, como vicio, y les da mono no ir a bailar.

No obstante, en la afirmación de algunos bailarines, aunque dicen entender que cada estilo tiene sus propias características, vemos cómo algunos estereotipos que habían mencionado antes de incursionar en el baile no han cambiado y establecen jerarquías entre los estilos de baile. El estilo de salsa en línea es más valorado que el estilo cubano, justamente uno de los estilos considerados más callejeros, respecto a los estilos que se enseñan en escuela.

En los casos de ciertos bailarines observamos, además de la modificación de hábitos a partir de su participación en el baile de escuela, ciertas transformaciones 


\section{perifèria}

Número 20 (2), diciembre2015

revistes.uab.cat/periferia

en la identidad. Algunos que empezaron siendo bailadores de calle, ahora son bailarines de escuela, no se sienten bien bailando estilo de calle, consideran que es un estilo que asocian con su pasado y ya no se identifican con él. Por otra parte, ciertos bailarines que no conocían la salsa, e incluso la rechazaban hace pocos años, ahora se definen como salseros.

En los bailadores y bailadoras no latinos también son evidentes ciertas transformaciones en su identidad a partir de su relación con el baile. En general las personas no latinas que entran en contacto y disfrutan con las músicas y bailes latinos, especialmente salsa y bachata, establecen un vínculo estrecho con estas músicas y su baile.

\section{Excursiones eventuales a las discotecas latinas y no latinas}

Como hemos dicho, desde el año 2000 los bailadores y bailarines en Barcelona suelen darse cita en espacios diferentes. En general, los bailadores latinos van a las discotecas que se dirigen al público de un país concreto, mientras que los bailarines no latinos suelen ir a salsotecas, discotecas o salas de baile dirigidas a la población autóctona. No obstante, dadas las relaciones interculturales entre latinos y no latinos, se da el caso de bailadores latinos que acuden ocasionalmente a las salas dirigidas al público no latino, así como también el de bailarines no latinos que asisten a discotecas de latinos. Igualmente, considerando las modificaciones de hábitos de bailadores no latinos y de bailarines latinos, hemos visto que a los bailadores no latinos no les gustan las discotecas de público primordialmente español -"todos bailan igual, no paran de girar"- y que los bailarines latinos prefieren las salas de baile donde van los bailarines de escuela, dicen que la música es "para bailador", "la música es muy buena", "hay muchos Dj que están muy actualizados"-. Las excursiones eventuales de latinos a las salas de público primordialmente español y las de no latinos a las discotecas de latinos obedecen a que en determinado día se programa un concierto o una fiesta que atrae a ambos tipos de público, por lo cual, ambos colectivos acuden a la discoteca o sala de baile que no suelen acudir. 


\section{perifèria}

Número 20 (2), diciembre2015

\section{revistes.uab.cat/periferia}

Aunque la motivación de asistir a una discoteca o sala de baile es pasarlo bien, los testimonios confirman que se "paga un peaje social" por estar en un espacio dirigido al público del que en principio, por la forma de vivir la fiesta y el baile, no se hace parte. A partir de las entrevistas y la observación participante podríamos citar muchos ejemplos que ilustran de qué manera las excursiones eventuales de no latinos a sitios de baile latinos y de latinos a sitios de baile español son penalizadas simbólicamente. Según los testimonios, algunas de las bailadoras no latinas que han asistido a discotecas de latinos las han cacheado en la entrada -"si te cachean es porque dentro puede pasar algo"-, si han ido a ver un cantante o una orquesta el horario de inicio del concierto ha sido varias horas más tarde del anunciado, por lo cual consideran que hay "mucha informalidad e irrespeto a la gente". El ambiente les ha parecido "bastante mal", "un poco cutre", "un poco raro", "un poco cargante" y han pensado que "los sitios donde solamente hay inmigrante y nada más que inmigrante es por algo". Cuando se podía fumar el ambiente estaba "cargado de humo" y en ocasiones han visto "mucho tipo enjoyado" e incluso tipos "llevando prostitutas". Por todos los inconvenientes expuestos les "cuesta llevar amigos españoles" y como en los sitios latinos la gente va en grupos, cuando les ha apetecido ir a alguna discoteca latina no les es fácil convencer a alguien que les acompañe. Por consiguiente, aunque estas bailadoras han querido ir a bailar y pasarlo bien, buscando la alegría y espontaneidad que han experimentado en algunos sitios de salsa y bachata de Barcelona o del extranjero y que no ven en sitios de baile de público primordialmente español, se han llevado decepciones cuando han asistido a determinadas discotecas latinas. Varias bailadoras manifiestan tener una frustración porque dicen "no encajar" y "aburrirse mucho" en los sitios de público español, pero los sitios de latinos tampoco les satisfacen.

De otro lado, los bailadores y bailadoras latinoamericanos cuando acuden a las discotecas y salas de baile dirigidas al público español en algunos casos no pueden entrar, por tanto sufren una penalización por el hecho de tener una apariencia no aceptada. Cuando pueden acceder experimentan una situación semejante a la anteriormente mencionada por las bailadoras no latinas: no encajan porque el baile que se práctica en estas salas es un estilo que no practican. Sin embargo, en el 


\section{perifèria}

Número 20 (2), diciembre2015

revistes.uab.cat/periferia

caso de los bailadores hombres latinos la situación varía, porque en el baile de la salsa y la bachata son los que dirigen a la pareja, por lo cual, si son buenos bailadores y sus rasgos fisonómicos y su presentación personal no corresponde a los estereotipos de los latinos que son rechazados por las mujeres no latinas, estas bailan sin mayor inconveniente con ellos, sean bailadoras o bailarinas de escuela. No sucede lo mismo con las bailadoras latinas, pues si el parejo prefiere bailar el estilo de salsa en línea y ellas no lo pueden seguir, les cuesta mucho responder o bailar de la manera que propone el hombre. Este desencuentro en el baile se da particularmente con los hombres que bailan de memoria, intentando hacer secuencias aprendidas en las clases, sin necesariamente bailar siguiendo el tempo de la música, cosa que no pasa con los bailadores no latinos que sí bailan espontáneamente dependiendo de la música que suena o con los bailarines no latinos que bailan preferentemente en el estilo cubano, dado la cercanía de este estilo con los diferentes estilos de baile de los latinos.

En cuanto a los bailarines de escuela, sean latinos o no, a veces asisten a una discoteca específicamente latina porque hay un cumpleaños o algún evento de un amigo y encuentran que la gente baila callejero o dicho de otra manera baila su estilo, pero, según los testimonios, los bailarines chicos y chicas prefieren el ambiente de las salas de público español donde van sus amigos de las escuelas de salsa porque les parecen más alegres, porque no hay gente sentada bebiendo alcohol y bailando exclusivamente entre el grupo que se conoce, sino que la gente tiene su cubata y baila con cualquiera. Este tipo de fiesta les parece mejor y también la música respecto a la de las discotecas de latinos. Como vemos, aunque los bailarines no latinos son muy criticados por no interesarse por la música que bailan, hay excepciones.

Bailarines y bailadores latinos y no latinos interesados por el baile y el disfrute de la música cada vez coinciden menos y tienen más difícil encontrar un lugar de fiesta de salsa y bachata más allá de los lugares especialmente dirigidos a una nacionalidad específica de latinos o dirigidos a los bailarines de escuela no latinos.

\section{A manera de conclusión: Latinidad Vs. Globalización}




\section{perifèria}

Número 20 (2), diciembre2015

\section{revistes.uab.cat/periferia}

El estudio de la salsa en Barcelona nos permite ver las diversas formas en que la salsa se entiende y se practica aquí, y sus conexiones con otras escenas de la salsa a nivel global. Igualmente, la escisión de la escena de la salsa que observamos en esta ciudad, señala el desarrollo de procesos locales respecto a la salsa como práctica global. Los españoles y latinos participan de una práctica cultural global, aunque de manera diferente. Los primeros están generalmente más vinculados con la salsa globalizada relacionada con los congresos y la salsa de estudio, mientras que los latinos evidencian las conexiones con la forma de vivir la salsa en los países de procedencia, es decir con la latinidad. En este sentido podemos decir que la escena de la salsa en Barcelona está caracterizada por tensiones entre los procesos de homogenización de la salsa frente a procesos de reafirmación de la diferencia.

La manera de relacionarse con la salsa por parte de los españoles suele separar el interés por la música de la experiencia del baile, mientras que para los latinos la coexistencia de la salsa, en tanto música como baile, tiende a asociarse con lo emocional y con la historia sentimental. Aunque para ambos colectivos el baile de la salsa puede ser relacionado con lo terapéutico (los latinos enfatizan que el baile lo cura todo emocionalmente, los españoles que el baile hace sentir bien) y el ejercicio, el aprendizaje del baile de la salsa se promueve entre los españoles en el sentido del fitness, es decir la práctica de la salsa como una actividad para estar en buena forma. Las parejas que participan en compañías que realizan montaje y presentación de coreografía, dado que es común que incluyan acrobacias y levantamiento de la pareja, requieren de los bailarines un estado físico y fortaleza para hacer dichos levantamientos, mientras que para las bailarinas el hecho de ser levantadas ejerce una presión respecto a la necesidad de pesar poco y no aumentar de peso.

En resumen, en los latinos el baile de la salsa aparece más relacionado con los sentimientos y las emociones, algunos refieren a asociación de la salsa con reivindicaciones políticas y sociales, mientras que no sucede lo mismo en el caso de los españoles, dada la relación de la salsa como práctica de academia, que en la actualidad es mayor que en la década de los noventa y en los primeros años de 2000 


\section{perifèria}

Número 20 (2), diciembre2015

revistes.uab.cat/periferia

A nuestro modo de ver, si bien la popularización del baile salsero de escuela ha contribuido a una relativa latinización de la cultura, la estandarización de pasos y técnicas, reprime la creatividad y la conexión cuerpo-sentimiento. Ante la imposición de los valores estéticos europeos legitimados por los congresos de baile, especialmente a través del estilo Los Ángeles (que incluye pasos de ballet, lo cual señala un blanqueamiento del baile salsero), de gran difusión en Barcelona,la manera de bailar de los latinos constituye una forma de resistencia. Esta afirmación podría ampliarse a otros lugares fuera de Barcelona, donde la salsa está siendo moldeada de acuerdo con los reglamentos de los congresos, que están devaluando el baile callejero, y por consiguiente, haciendo necesario acudir a cursos para aprender a bailar salsa, incluso en lugares donde se había aprendido por imitación, en las casas durante las fiestas familiares o con amigos. No hay que olvidar que el debate entre cuál estilo de salsa es mejor está relacionado con el interés económico y comercial alrededor del baile.

\section{Bibliografía}

Bourdieu, Pierre(1998). La Distinción: Criterio y bases sociales del gusto. Madrid: Taurus.

Desmond, Jane (1997). Meaning in motion: new cultural studies of dance. Durham: Duke University Press.

Escalona, Saúl (2010). Si la Peña m'etait contee...! : Une histoire de la Salsa a Paris. París: L'Harmatan

Hutchinson, Sydney (ed). (2014). Salsa World: A Global Dance in Local Contexts. Philadelphia, Pennsylvania: Temple University Press.

Llano Camacho Isabel (2014). "Salsa in Barcelona and Spain" en Salsa World: A Global Dance in Local Contexts. Ed.Sydney Hutchinson. Philadelphia, Pennsylvania: Temple University Press, pp. 182-199. 


\section{revista de recerca i formació en antropologia}

\section{perifèria}

Número 20 (2), diciembre2015

revistes.uab.cat/periferia

Martí i Pérez, Josep (2008). "La fiesta en el escenario urbano actual" en Fiesta y Ciudad: pluriculturalidad e integración. Josep Martí i Pérez (Editor). Madrid: CSIC, pp. $13-40$.

Sánchez Fuarros, Iñigo (2008). "iEsto parece Cuba!" Prácticas musicales y cubanía en la diáspora cubana de Barcelona. UB. Facultat de Geografia i Historia. Departament d'Antropología Social i Història d'América i Àfrica.Trabajo de investigación de segundo año en el programa de Doctorado en Antropología Social y Cultural (2003-05). Codirigida por Josep Martí i Pérez y Gemma Orobitg Canal.

Renta, Priscilla (2014). "The Global Commercialization of Salsa Dancing and Sabor (Puerto Rico)" en Salsa World: A Global Dance in Local Contexts. Ed.Sydney Hutchinson. Philadelphia, Pennsylvania: Temple University Press, pp. 117-139.

Román-Velásquez, Patria(1999). The Making of Latin London. Salsa music, place and identity.Hants, England: Ashgate.

Ulloa, Alejandro (2005). El baile, un lenguaje del cuerpo. Cali: Secretaría de Cultura y Turismo del Valle del Cauca.

Wade, Peter (2000). Music, race and Nation. Música tropical in Colombia. Chicago: The University of Chicago Press. 